\title{
MODEL TRANSPORTASI MENGHITUNG BIAYA TERENDAH MENGGUNAKAN METODE MODIFIED DISTRIBUTION (MODI)
}

\author{
Wahyu Sofyanti Dewi, E.N Tamatjita, Yuliani Indrianingsih \\ Program Studi Teknik Informatika \\ Sekolah Tinggi Teknologi Adisutjipto Yogyakarta \\ tamatjita@yahoo.com, yulistta@gmail.com
}

\begin{abstract}
Modified Distribution (MODI) method of the operation research's in Sekolah Tinggi Teknologi Adisutjipto Informatic Engineering is one of method which optimal solution low cost in the transportation model. MODI is using Northwest Corner method to determine the initial allocation, which will be processed to obtain a more optimal solution. MODI method is aplied to a desktop-based application that aims to help lecturer on presentation material. The results of 2 test on 1 primary user respondent 85,81\% for 30 questions, test of 30 secondary user respondent with, Display/Graphical User Interface (GUI) (74,67\%), Speed/Conveniences Of Access to information (80,92\%), Accuracy Of Information (82,89\%), and User Satisfaction (81,90\%). Low cost application of Transportation Model with MODI method is very good.
\end{abstract}

Keywords : Transportation Model, Northwest Corner, MODI, Optimal Solution.

\section{Pendahuluan}

Pada mata kuliah Riset Operasi yang merupakan mata kuliah pilihan wajib, terdapat pembahasan suatu metode yang dikenal dengan Modified Distribution (MODI). Metode MODI digunakan untuk menentukan biaya terendah, misalnya ketika ingin mengirim barang dari berbagai sumber ke berbagai tujuan. Metode MODI merupakan metode yang agak rumit sehingga sering membuat mahasiswa kesulitan memahaminya. Selain itu, pembelajaran metode MODI disampaikan secara manual, yaitu dengan menggunakan media papan tulis menyebabkan waktu yang digunakan untuk belajar kurang efisien. Oleh sebab itu, dibutuhkan software yang dapat digunakan untuk membantu proses belajar tersebut.

\section{Metodologi}

\subsection{Tinjauan Pustaka}

2.1.1 Perancangan Aplikasi Distribusi Obat Generic Dengan Metode MODI Berbasis Web

Penelitian ini menjelaskan tentang analisa saplikasi yang menggunakan metode Modified Distribution (MODI) untuk mendistribusikan obat Generik dengan studi kasus pada PT. Kimia Farma.

\subsubsection{Optimasi Pendistribusian Air Dengan Menggunakan Metode Least Cost Dan Metode Modified Distribution}

Penelitian ini menjelaskan tentang analisa sistem pendistribusian air dengan menggunakan metode Least Cost dan metode Modified Distribution (MODI) dengan studi kasus pada PDAM Kabupaten Minahasa Utara.

2.1.3 Aplikasi Metode Stepping Stones untuk Optimasi Perencanaan Biaya pada Suatu Proyek Konstruksi

Penelitian ini menjelaskan tentang penerapan metode Stepping Stones dalam sebuah aplikasi untuk menghitung solusi optimal pada proyek konstruksi dengan studi kasus pada Proyek Pemeliharaan Ruas Jalan di Senduk, Tinoor, dan Ratahan. 


\subsection{Landasan Teori}

\subsubsection{Model Transportasi}

Metode transportasi berhubungan dengan distribusi suatu produk tunggal dari beberapa sumber dengan penawaran terbatas, menuju beberapa tujuan, dengan permintaan tertentu. Tujuannya adalah untuk mencapai solusi optimal yaitu menghasilkan biaya terendah.

\subsubsection{Northwest Corner}

Metode Ujung Barat Laut atau Northwest Corner Method merupakan metode yang digunakan untuk pencarian biaya awal pada model transportasi.

\subsubsection{Modified Distribution (MODI)}

Metode Modified Distribution (MODI) atau Faktor Pengali (Multiplier) merupakan metode yang dikembangkan berdasarkan teori dualitas. Metode MODI merupakan metode yang digunakan untuk menentukan solusi optimal pada model transportasi.

\section{Analisa dan Perancangan Sistem}

\subsection{Analisa Sistem}

\subsubsection{DFD Konteks}

DFD Konteks adalah diagram yang mencakup masukan-masukan dasar, sistem umum, dan keluaran.

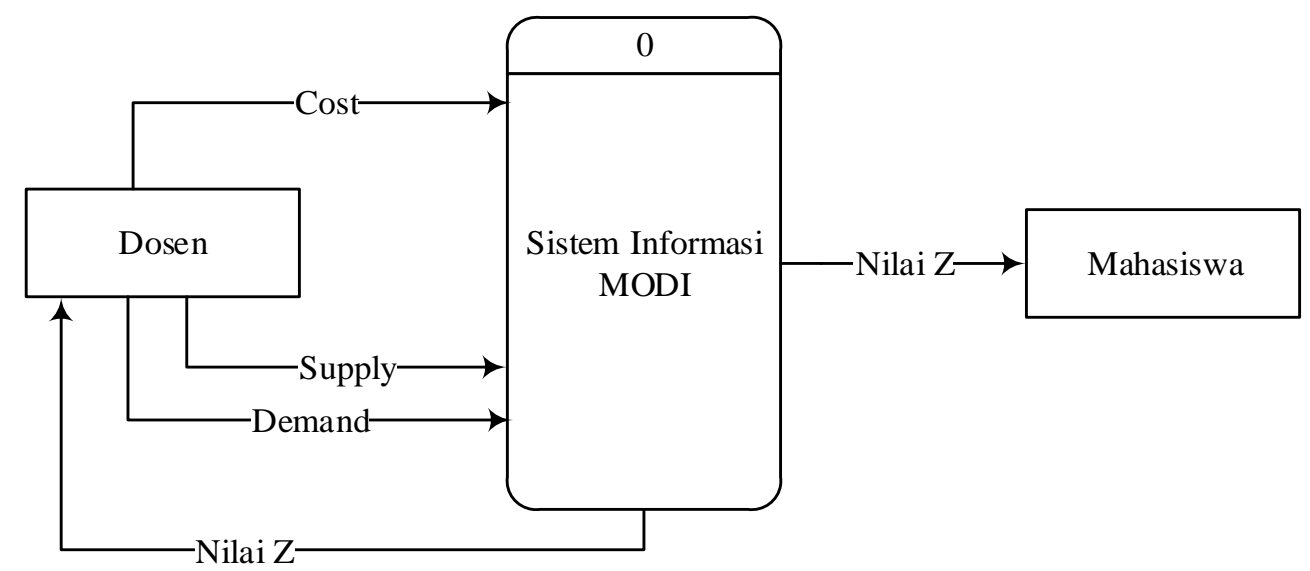

Gambar 1 DFD Konteks Sistem Informasi MODI 


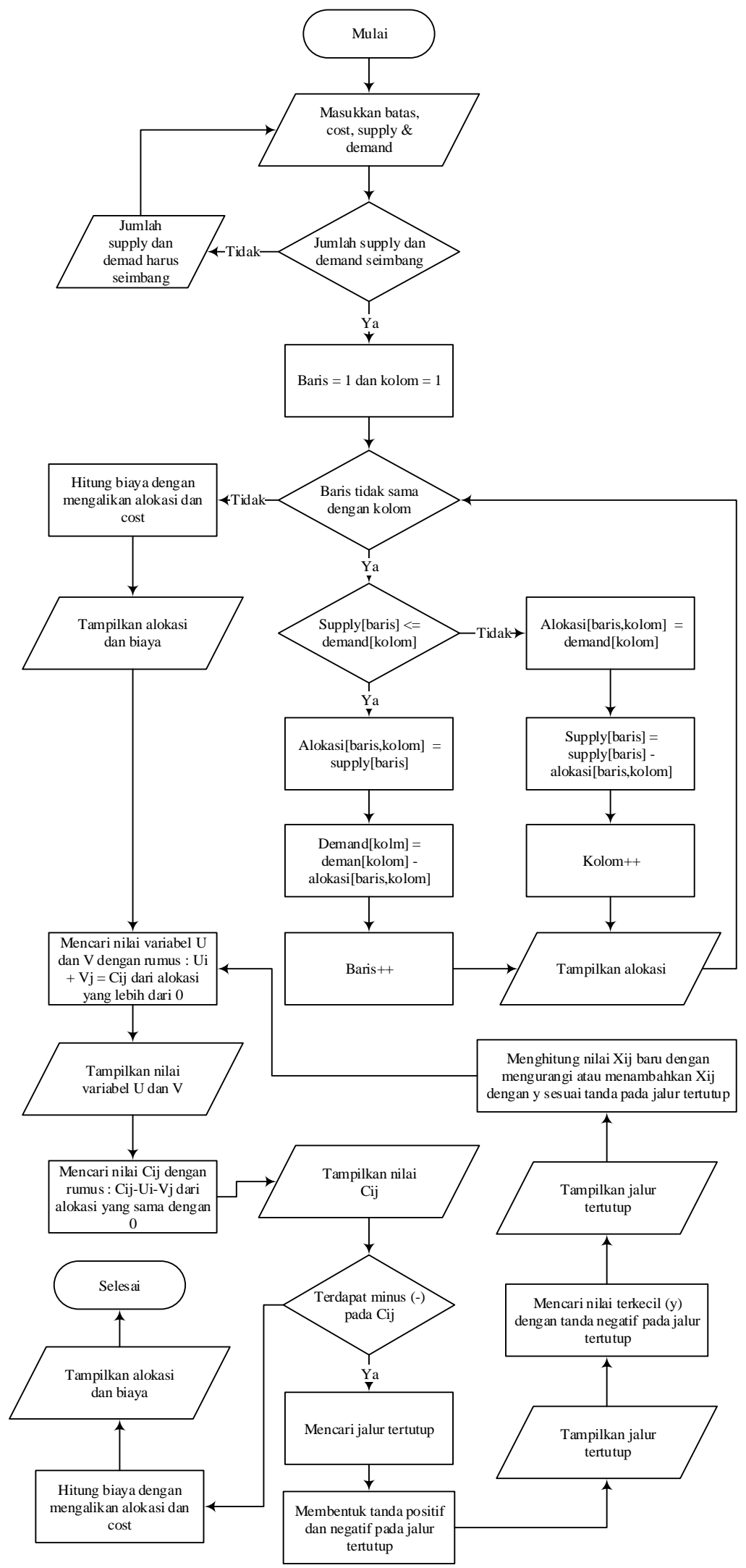

Gambar 2 Flowchart Program MODI

\subsection{Perancangan Interface}

Perancangan Interface membahas mengenai perancangan tampilan atau user interface dari program MODI. Interface ini meliputi Menu Utama dan Menu Masukkan. 


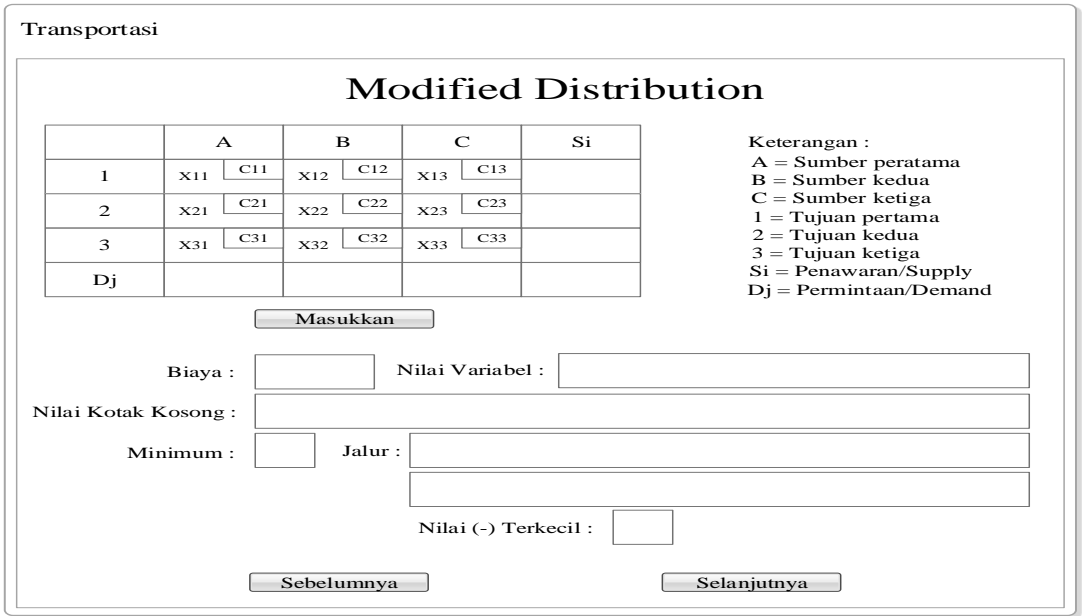

Gambar 3 Perancangan Interface Menu Utama

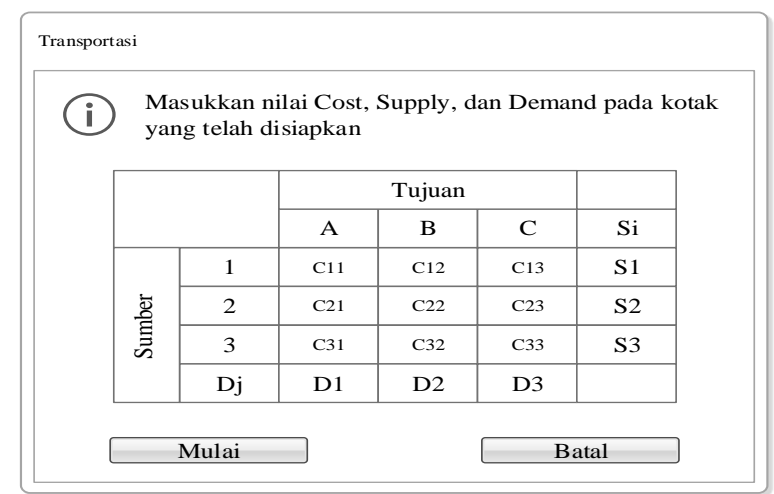

Gambar 4 Perancangan Interface Menu Masukkan

\section{Implementasi dan Analisa Hasil}

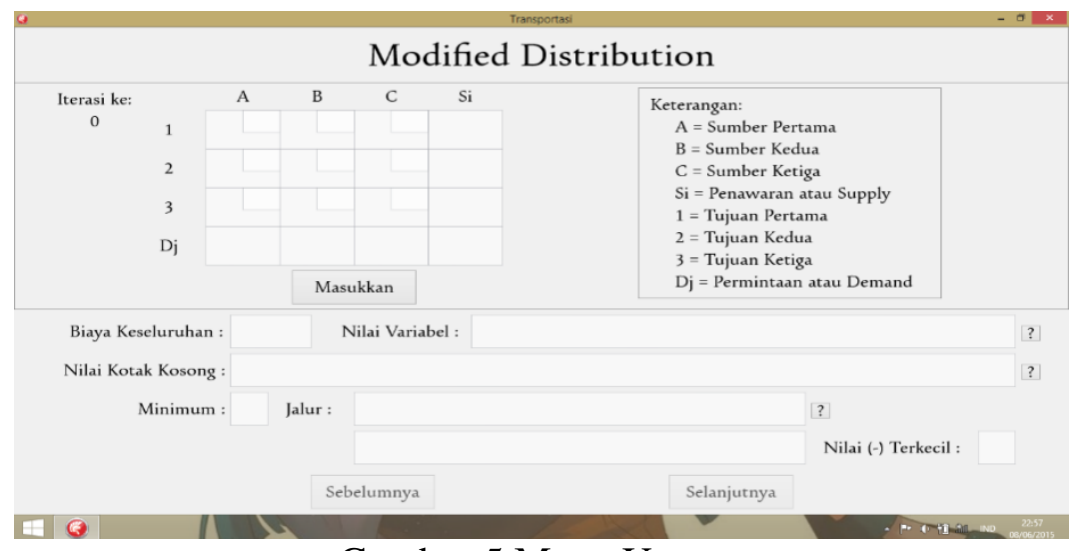

Gambar 5 Menu Utama 


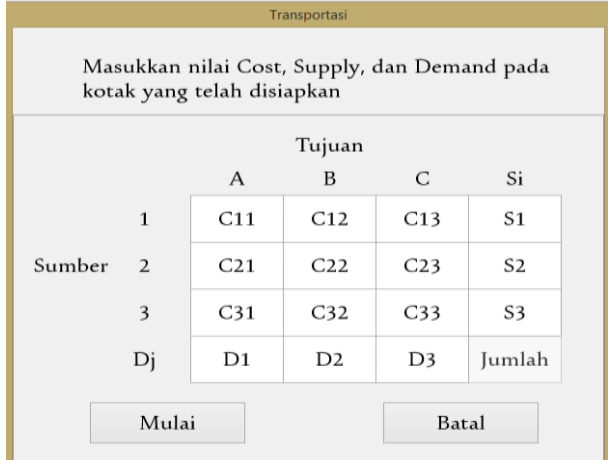

Gambar 6 Menu Masukkan

\subsection{Analisa Hasil Aplikasi MODI Terhadap Pengguna}

Pengujian aplikasi MODI dilakukan dengan menggunakan kuisioner yang dihitung berdasarkan metode Likert. Hal ini dilakukan dengan tujuan untuk menentukan apakah aplikasi MODI baik atau tidak. Jumlah Dari Responden : : 30 orang Jumlah Pertanyaan : 30

Kriteria Interpretasi : Angka 0\%-19,99\% = Sangat tidak baik

Angka 20\%-39,99\% = Tidak baik

Angka $40 \%-59,99 \%=$ Cukup

Angka $60 \%-79,99 \%=$ Baik

Angka $80 \%-100 \%=$ Sangat baik

Berdasarkan Tabel 1 hasil rata-rata persentase aplikasi MODI adalah 78,84\% dengan demikian masuk kriteria Baik.

\section{Penutup}

\subsection{Kesimpulan}

Berdasarkan implementasi dan uji coba sistem pada bab sebelumnya, dapat diambil kesimpulan sebagai berikut:

1. Tampilan aplikasi MODI sesuai dengan standar sehingga nyaman digunakan, hasil ini didapatkan melalui pengujian terhadap 1 orang responden primary user dengan 30 pertanyaan yang memperoleh nilai $85,81 \%$.

2. Aplikasi MODI dapat menghitung biaya terendah dengan menggunakan metode Modified Distribution (MODI) dan menghasilkan data yang akurat sesuai dengan perhitungan secara manual dalam waktu yang singkat, didapatkan hasil melalui pengujian terhadap 30 responden secondary user yaitu, Tampilan/Graphical User Interface (GUI) adalah 74,67\%, Kecepatan/kemudah akses informasi adalah 80,92\%, Keakuratan Informasi adalah 82,89\%, serta Kepuasan pengguna/user adalah 81,90\%.

3. Dari hasil kedua pengujian diatas terhadap aplikasi MODI, membantu mahasiswa dalam mempelajari model Transportasi khususnya metode Modified Distribution (MODI) yang dipelajari pada mata kuliah Riset Operasi jurusan Teknik Informatika Sekolah Tinggi Teknologi Adisutjipto dengan lebih baik.

\subsection{Saran}

Aplikasi MODI tentunya masih memiliki banyak kekurangan. Oleh sebab itu, untuk pengembangan kearah yang lebih baik didapatkan beberapa saran antara lain:

1. Sebaiknya menampilkan lebih detail mengenai langkah-langkah pengerjaan setiap hasil yang ada. Tampilannya dibuat lebih menarik, seperti menambahkan warna atau dapat dibuat menjadi animasi sebagai simulasi perhitungan metode MODI.

2. Perhitungan MODI diperluas menjadi ordo $\mathrm{m} \times \mathrm{n}($ contoh : $3 \times 4,4 \times 3$, atau $4 \times 4$ dan seterusnya). 
3. Menambahkan beberapa bank soal dalam program sehingga bisa jadi panduan untuk user menyelesaikan kasus-kasus yang berkaitan dengan riset operasi terkait implementasi program Modified Distribution (MODI).

\section{Daftar Pustaka}

[1] Ali, Nurjuliawati P.H. 2013. Aplikasi Metode Stepping-Stone untuk Optimasi Perencanaan Biaya pada Suatu Proyek Konstruksi (Studi Kasus: Proyek Pemeliharaan Ruas Jalan Di Senduk, Tinoor, Dan Ratahan), Manado.

[2] Jogiyanto, HM. 2005. Analisis dan Desain. Bab 2. Hal. 41-52. Yogyakarta: ANDI.

[3] Nelwan, Claudia, dkk. Optimasi Pendistribusian Air dengan Menggunakan Metode Least Cost dan Metode Modified Distribution (Studi Kasus: PDAM Kabupaten Minahasa Utara), Manado.

[4] Purba, Nasip. 2013. Perancangan Aplikasi Distribusi Obat Generik Dengan Metode MODI Berbasis Web (Studi Kasus : PT. Kimia Farma), Medan.

[5] Taha, Hamdy A. Riset Operas Jilid Satu. Bab 6. Hal. 202-230. Binarupa Aksara Publisher.

[6] Tamba, Mariani. 2014. Aplikasi Minimalisasi Biaya Transportasi Pengiriman Barang Menggunakan Vogel's Approximation Method (VAM) Studi Kasus CV. Tao Toba Indah, Medan.

[7] Valacich, Joseph, dkk. 2011. Essentials of System Analysis and Design Fifth Edition. Chapter 6. Hal. 155-164. Pearson Education, Inc. 